\title{
Similarities and differences between green, sustainable and healthy building concepts
}

\author{
Huda Abdul Sahib Al Alwan and Ebtisam Sami M. Saleh \\ \{hodaalwan@yahoo.com, uloom2004@yahoo.com\} \\ College of Engineering University of Baghdad, Building Research Directorate \\ Ministry of Construction and Housing, Baghdad, Iraq
}

\begin{abstract}
This paper is an attempt to put each term (green, sustainable and healthy building) within the scientifically and historically correct framework and eliminate the confusion by clarifying points of similarities and differences between them. New concepts and methods have emerged in designing and constructing buildings, such as green, sustainable, and healthy buildings. These concepts are ideas that we hear all of the time, however, they are rarely properly understood, especially the words "green" and "sustainable" are often used interchangeably, but being "green" and being "sustainable". The absence of a comprehensive theoretical framework that can define the similarities and differences between these concepts formed the main problem of the study.
\end{abstract}

analytical and comparison methods employed in this study by collecting data from many related sources and analyzing it to get the final results. The results showed that there is a big difference between the three concepts.

Keywords: green, sustainable, healthy building, health, sustainability, sick building.

\section{Introduction}

New concepts and methods have emerged in designing and constructing buildings, such as green, sustainable, and healthy buildings.

We hear a great deal about"going green", "sustainability" and "healthy living" in the media and in discussion consistently, yet what does it truly mean? Do they have the same concept or there are differences between these concepts? In a clear realizing of these differences belongs the key to realizing the broad range of approaches, programs, agendas regulations, techniques, and technologies that are confusingly assembled under the mantle of "sustainable building". This paper argues that if green buildings and sustainable buildings are the same? Are all green or sustainable buildings healthy buildings? Green, sustainable and healthy buildings these terms are without a doubt related, yet do they truly mean something very similar for buildings? If we are building a greener or a sustainable building, would we say we are certainly getting a greener one? 
Although "green" and "sustainable" are often used mutually, there are important diverging between what is "green" what is "sustainable" and what is "healthy" To get a more realizing of where these diverging lie, we might start with a brief history and definition of these concepts.

\section{History of green buildings}

Green building history dates back in the midst of the industrial revolution, where "Henri Becquerel" first saw the renewal of solar energy into electrical energy, known as "photovoltaic power". In the late 1800s to early 1900s, a number of solar power plants were built to benefit the sun's energy for steam power. During the 1950s, solar energy was used (on an extremely small-scale) clearing a path for the solution of solar panels twenty years after the fact.

At the time of the energy crisis of the 1970s, the green building moved from innovative work to the real world. Designers and architects were searching for an approach to decrease the dependence of buildings on petroleum products. Utilizing solar panels and making more environmentally friendly buildings, just in little numbers because of high beginning expenses. From that point forward, engineers have had the option to develop increasingly productive and more affordable solar panels [21].

So it has grown to be synonymous with environmentally-friendly buildings, which is why it was is called green, like a plant that succeeds in its place and benefits from the environment to meet its requirements. So a designer who makes a green structure could imply that it is vitality effective, yet similarly, it could just imply that there are solar panels on the rooftop while the remainder of the plan stays unaltered.

By all above the reasons for advocating for green architecture is the environmental problems that have arisen as a result of the excessive exploitation of natural resources, the increase of pollutants, harmful waste due to the industrial revolution, the need to reduce operating costs and the effect of sealed buildings "the sequence of oil embargo" on the health of its occupants [24].

\subsection{Definition of green building oncept}

Green design, or Green architecture, is a way to deal with the building that limits adverse effects on the environment. The "green" designer or architect attempts to safeguard water, air, and earth by picking eco-friendly building construction practices and materials [13].

It has been defined by William Reed's as: buildings designed, implemented and managed in a manner that takes the environment into account, it reduces the building's impact on the environment while minimizing construction and operating costs. 
In another definition for green building design: "It refers to an environmentally friendly style or design of the building, these are the means of construction that tend to hinder or largely reduce the effect it may possess on the environment".

\section{History of sustainable buildings}

Sustainable architecture has become part of the world's sustainability system, and it has emerged in the last decade of the twentieth century. "Our common future", also known as "The Brundtland Report", from the "United Nations World Commission on Environment and Development" was advertised in 1987. The publication of "Our Common Future" and the work of the "World Commission on Environment and Development" laid the basis for the formation of the "Commission on Sustainable Development" and defined sustainable development as: "development that meets the needs of the present without compromising the ability of future generations to meet their own needs" [18].

The "Brundtland Commission" contended that social and economic systems couldn't be separated from the "carrying capacity" of the environment - the possibility that development and social welfare must be adjusted by the preservation of ecological assets by the present age to assist people in the future. Consequently, the expression "sustainable development" has wide repercussions for designers - the individuals who are doing the "development". In any case, it likewise makes one wonder economic whether and environmental sustainability is genuinely reconcilable [18]. In 1992 The "United Nations Conference on Environment and Development", held in "Rio de Janeiro" gave the fundamental program and the principles of actions for accomplishing "sustainable development" [14]

The concept of "sustainable consumption and production" was introduced in 2002 by "Johannesburg World Summit on Sustainable Development" motivating a number of international agreements. The key guideline was to establish a link between resource use, levels of pollution, and productivity. In particular, the agreement was about:

- Ensuring that economic development doesn't cause ecological contamination at a local and global level.

- Resource use efficiency improvement.

- Examining the entire life pattern of a product.

- Giving buyers more data on services and products.

- Exploiting regulation and taxation to encourage development in "clean technologies" [18].

In summary, the goal of "sustainable architecture" is to minimize the strong effect that is done by destructing natural areas used for building, air alternation, and energy or hydro consumption. This development goes to the way that the uncontrolled utilization of natural 
resources will become a serious risk to our lives later on. The activity calls for a unified and synergistic design [20].

\subsection{Definition of sustainable building oncept}

The "World Commission on Environment and Development" has defined "sustainability" as: "meeting the needs of the present without compromising the ability of future generations to meet their own needs" [15]. The "sustainability movement" is not just about the protection of the environment, but instead about finding a careful balance between the economics, environment, and social justice [19]. The "Pranditland Commission" has attempted to integrate economic development with conservation and natural resource trends called sustainable development. This definition is based on two basic concepts: the concept of needs in line with the circumstances to maintain an acceptable standard of living standards for all human beings. The second is the concept of limits to the ability of the environment to meet current and future needs that are associated with social organization and technological developments [20].

another definition of sustainability from the "Environmental Protection Agency": "Sustainability creates and maintains the conditions under which humans and nature can exist in productive harmony, that permit fulfilling the social, economic and other requirements of present and future generations"[20].

Sustainable architecture is about minimizing a building's impact on its environment over its life. So "Future" factors set a better quality for sustainable activities and products.

\section{History of healthy buildings}

During the 1970s the energy crises and recognition of environmental problems in terms of "healthy buildings" [4], and the idea of health promotion around med 1980s [7]. It is essential to recognize that, although indoor air quality (IAQ) is a significant determinant of "healthy design", it isn't the sole determinant. Other parameters include acoustics, vibration, lighting, comfort, aesthetics, and security, along with ergonomic design factors and safety[6], also many properties of the built environment such as smell, aesthetic qualities, sound, social aspects, control, privacy, and so on are understood to have the probable influence on the health of a person through the physiological and the psychological systems of the human body [8].

A good details on the bases of healthy building for better enevronment for people to work [11]. In the 1970s a high prevalence of symptom complaints among the occupants of many buildings was reported in several countries, at which a strong correlation with the attendance in the building was identified. This has been termed Sick Building Syndrome by a working group of the World Health Organization in the 1980s [2].

It is declared by WHO the gruesome building resulted from many factors in 1982 such as physical, air quality and psychosocial matters. This building might be called as sick building 
syndrome (SBS) related to many irritations symptoms, reported by workers. SBS appears to have relation to the time spent in buildings but without strong evidence $[1,12]$.

There is quite relation between the inhabitant and healthy building to wards the wider concept to improve the building envreonment; however there are still factors to be considered $[4]$.

\subsection{Definition of health}

(WHO) definition of health is: "a state of complete physical, mental, and social well-being and not merely the absence of disease or infirmity". It is expected that biomedical emphasis based on human psychological, biological, and social functioning. This might also include other human factors by [10], also many studies, have documented the connection between body and the mind [8]. Our psychological and physiological system is not "separate and distinct from our experiences in life" [8].

Similarly, health is a physical state and has emotional facets. Physical health can be improved through physically healthy buildings and architectural ergonomics, while the emotional side is connected to abstract aspects of the architecture [7]. So the term "human environment" has evolved to embrace the physical and the psychological aspects of an environment that consists of the interactional, social, transactional and organizational aspects that might affect mental health and wellbeing [8]. The spaces that we occupy on an everyday based on emotional reactions impacts on health and wellbeing [9].

\subsection{Definition of healthy building concept}

Focusing only on one requirement, a "healthy building" can be defined as: "one that is harmful neither to its occupants nor to the larger environment". This is an inadequate definition because there must also be a favorable environment, one that is aesthetically and functionally supportive of healthy lives. Aesthetically it must be pleasing, harmonious, and peaceful. Functionally it must fulfill the essential needs of the inhabitants in a supportive and healthy way. [17].

The "healthy building movement" infesizes that "buildings have the potential for both positive and negative impacts on people and the environment, and the desire to mitigate negative impacts while enhancing those features that provide positive benefits.

There is no hazardous materialtowards the health of the inhabitants during its whole life cycle, enhancing productivity and social needs. A "healthy building" admits that occupants' health needs, are priorities. In addition to that, it should be ready for the future, the change towards a multifunctional and diverse society, adaptable to "new drivers" such as climate change, the increasing individualization [5].

Many indoor environmental issues that must be addressed to avoid adverse effects on occupants' health and well-being, which must be considered, are the quality of light, thermal, acoustic, security, privacy, and functional suitability. Buildings must not adversely affect the general environment. It must have minimal adverse effects on the general environment at all 
levels "construction, operation, use, and ultimate disposition" or ultimately it will have an adverse effect on people whether indoors or outdoors [3].

\section{Comparison, analysis and discussion}

We have applied an analytical comparison method in this study to find out the similarities and differences between the three concepts adopted, for the comparison, first, we will compare between the first and the second concept "green and sustainable" and then we will compare them with the third concept "healthy"

\section{Part1: green and sustainable}

The term "green growth" is usually combined with the term "sustainable development" or sometimes used in its place. The differences between the concepts of green and sustainable are not verbal or abstract, and the equality of the two concepts is inaccurate [16].

The green building is the building that minimizes the impact it has on the environment while "sustainability" requires the custodial operation to look at a product's entire life cycle, from crib to grave. This means implies thinking about how natural materials were obtained, how the product was made, and transported, what sorts of packaging was used and the reusing or disposal of it.

"Green design" is not the same as "sustainable design", although it a subset of it. Reducing environmental effect is a worthy goal and a significant discipline, however, it's often far from seeking sustainability. "Sustainable design" is also a method which, in addition to the environmental, strives to acknowledge the economic and social ramifications (for initiators) of a task as well. Any product to be described as sustainable should be the way it is manufactured, transported and operated so as not to exhaust resources, damage the surrounding environment or air pollution. This means that a specific product can be green in its final application, but it may not be "sustainable" in its initial application and manufacture. There is an important fundamental difference between "green" and "sustainable" [16].

First, sustainability importance lies in the "future" factors, to define "green building". "Sustainability" is focused on the far off future (30 to 50 years). Any actions taken under the name of "sustainability" must address the effect of present actions on conditions prone to win in that future time frame.

Second, a key concept of sustainability is avoiding waste, so any building that is strictly bigger than it needs to be isn't really sustainable. Also, a building that looks as if it has emerged naturally from its surroundings can have very inefficient construction in terms of thermal performance and relies on burning lots of fuel to operate comfortably. Conversely, you can have a sustainable building that has a very high level of technical performance but uses an overtly technological approach to obtain it.

Third, "sustainable" however is a more precise term used mostly for process or product that can be reused. 
So green isn't always sustainable, sustainable design is more than a green design or a higher degree. see these examples:

Bamboo flooring is green (bamboo can grow for harvest within five years and then be cut and grow again on its own), but most is not "sustainable" because our supply of this fuel is limited and because of the contributions to global climate change by burning this fuel.

This means that the use of green products does not necessarily mean that the building is sustainable or energy efficient.

In another example, a green car can "because it manages to less gasoline than other cars" will reduce pollution and negative environmental effect but it's not "sustainable". Another example of a green paper towel (a product) usually consists of recycled fibers from pre-cut trees. In order for the product to be sustainable, the plant owner must act in a sustainable manner by planting a new tree for each tree used to construct these towels to fill the gaps in the forest for future generations.

It is very significant to asses the way of producing and transporting materials. The manufacturing, transportation, and powering of a product have to be done in a way that doesn't exhaust resources or mar the surrounding environment or pollute the air, so as to term this product "sustainable".

\section{Part2: green, sustainable and healthy}

For the differences between green, sustainable and healthy concepts, the nonprofit "U.S. Green Building Council", which administers "LEED", recognized gaps in the standard, to enhance human health and the environment [23]. The "gold standard" for certifying "green buildings" fails to place adequate emphasis on human needs and health to be enhanced, according to a report from an "environmental health group" [23]. Healthy building is a term that dates back to the 1980s, but its use was not common until the end of the 1990s. A number of architects are preparing a healthy building is the result of large movements towards providing health and good condition as a new principle or element of sustainability. Healthy buildings are the next chapter of green buildings and sustainable buildings.

A good study was performed on building positive impacts rather than sustain the wellbeing process of building [22]. There are a couple of big moves we are seeing out there, and one is the introduction of health and well-being as another element of green and sustainability.

There is a need for a new vision in which architecture focuses on human occupants' wellbeing. despite the present preoccupation with "sustainable" practices often leads to more Although, habitable buildings, it is still concentrated on technology instead of the occupant, table (1) [7]. 
Table 1. Brief of the comparison between the three concepts.

\begin{tabular}{|c|c|c|}
\hline Green building & Sustainable building & Healthy building \\
\hline $\begin{array}{l}\text { minimizes the environment } \\
\text { impact due to the design } \\
\text { procedures. }\end{array}$ & $\begin{array}{l}\text { look at a building's whole life } \\
\text { cycle, from crib to grave } \\
\text { (including demolition or } \\
\text { disassembly) }\end{array}$ & $\begin{array}{l}\text { look at a building's whole life } \\
\text { cycle, from crib to grave } \\
\text { (including demolition or } \\
\text { disassembly) }\end{array}$ \\
\hline $\begin{array}{l}\text { Hard to achieve suitable emphasis } \\
\text { on human health }\end{array}$ & $\begin{array}{l}\text { Hard to achieve suitable } \\
\text { emphasis on human health }\end{array}$ & $\begin{array}{l}\text { Support and protect health ethos } \\
\text { for better wellbeing. }\end{array}$ \\
\hline Focused on the current state & $\begin{array}{l}\text { Focused on the distant future for } \\
\text { the building and its components }\end{array}$ & $\begin{array}{c}\text { Focused on the distant future for } \\
\text { the building and its and } \\
\text { occupants }\end{array}$ \\
\hline $\begin{array}{l}\text { Term used mostly for process or } \\
\text { product that has little impact on } \\
\text { the environment }\end{array}$ & $\begin{array}{c}\text { In addition to the environmental, } \\
\text { strives to at least acknowledge } \\
\text { the social and economic } \\
\text { ramifications } \\
\text { Sustainable is still focused on } \\
\text { the environment instead of the } \\
\text { building occupant }\end{array}$ & $\begin{array}{l}\text { Term used mostly for process or } \\
\text { product that has no negative } \\
\text { impact on the environment and } \\
\text { buildings occupants }\end{array}$ \\
\hline Green isn't always sustainable & $\begin{array}{l}\text { Sustainable is more than green } \\
\text { design, it is a higher degree. } \\
\text { So sustainable is always green }\end{array}$ & $\begin{array}{l}\text { Healthy buildings are the next } \\
\text { chapter of green and sustainable } \\
\text { buildings. It is the introduction } \\
\text { of health and well-being as } \\
\text { another element of green and } \\
\text { sustainability }\end{array}$ \\
\hline Green is a subset of sustainable & Sustainable includes green & $\begin{array}{c}\text { Healthy is a green and } \\
\text { sustainable building as well as it } \\
\text { contributes to improving the } \\
\text { mental state of its occupants } \\
\text { through its design } \\
\text { characteristics. }\end{array}$ \\
\hline
\end{tabular}

\section{Conclusion \& recommendation}

So is there really a big difference in green, sustainable and healthy buildings? Yes, it has been shown that there are differences between the concept of green, sustainable and healthy building, but there are also links between them.

Green is a subset of sustainable and support health to improving the mental state of its occupants through its design characteristics.

By designing buildings that have a holistic approach (healthy buildings), architects can consider the wider impacts on climate, environment, and its occupants. That's not to say we should stop building green or sustainable buildings. Those other goals are also important, but the term (healthy building) should be qualified by more people so that we are holistically improving the places where we spend the vast majority of our lives. Our endeavors in making "green buildings" ought to be comprehensive to incorporate a product which is healthier for the environment, but also a healthier environment for us. 
We can say that when we build a healthy building, we build a green and sustainable building. The goals must be more comprehensive to improve our health, the places and environment in which we live altogether

\section{References}

[1] Brauer, C.: The Sick Building Syndrome Revisited. Ph.D. thesis, Department of Occupational Medicine, University of Copenhagen, 2005.

[2] Chuen, L.: The Concept of Safe Indoor Air Quality for the Management of Indoor Environment in Immune Buildings. Ph.D. thesis, Department of Building Services Engineering, The Hong Kong Polytechnic University, 2010.

[3] Levin, H. \& Associates.: Building Ecology: An Architect's Perspective on Healthy Buildings. Presentation as a keynote lecture at "Healthy buildings '95," main, Italy, September 10-15, 1995.

[4] Levin, H.: Design and Construction of Healthy and Sustainable Buildings. Building Ecology Research Group, Santa Cruz, USA, 2000.

[5] Philomena, M.: Towards New Methods and Ways to Create Healthy and Comfortable Buildings. Journal of Building and Environment, The Netherlands, 2010.

[6] Spengler, J., Chen, Y. \& Dilwali, K.: Indoor Air Quality Factors in Designing a Healthy Building. in Indoor Air Quality Handbook, Chapter 5, McGraw-Hill, 2004.

[7] Steemers, K. \& Manchanda, S.: Energy Efficient Design and Occupant Well-being: Case Studies in the UK and India. Journal of Building and Environment, Volume 45, Issue 2, February, 2010

[8] Suresh, M., Smith, D. \& Franz, J.: Person Environment Relationships to Health and Wellbeing: An Integrated Approach. School of Design, Queensland University of Technology, Australia, 2006.

[9] Suresh, M., Franz, J. \& Smith, D.: Interior Design from an Integrative Health Systems Perspective Reveals the 'Hidden Dimension'. Proceedings At Risk Conference, Wellington, New Zealand, 2007.

[10] Veitch, J.: Investigating and Influencing How Buildings Affect Health: Interdisciplinary Endeavours. National Research Council Institute for Research in Construction, Canadian Psychology, Vol. 49, No. 4, 2008.

[11] WHO: Indoor Air Quality and the Use of Energy in Buildings. Office for Official Publications of the European Communities, Report No. 17, 1996.

[12] Yin, N.: Impacts of the Indoor Environment on the Health of Occupants in Open -Plan Offices in Hong Kong. A study of the Department of Real Estate and Construction, Faculty of Architecture, Hong Kong, April 2004.

[13] Ragheba, A., El-Shimyb, H. and Raghebb, G.: Green Architecture: A Concept of Sustainability. Urban Planning and Architecture Design for Sustainable Development, UPADSD 14- 16 October 2015, Published by Elsevier Ltd. 2016

[14] United Nations, Report of the World Summit on Sustainable Development Johannesburg, South Africa, 26 August- 4 September 2002

[15] Kim, J. and Rigdon, B.: Sustainable Architecture Module: Introduction to Sustainable Design. College of Architecture and Urban Planning, The University of Michigan, Published by National Pollution Prevention Center for Higher Education. 1998 
[16] Lukachko, A. and Lstiburek, J.: Towards Sustainability: Green Building, Sustainability Objectives, and Building America Whole House Systems Research. Building America Report - 0801, February-2008

[17] Levin, H.: Designing Healthy Houses and Cities: The Roles of Architects and Science. International Symposium on Current Status of Indoor Air Pollution by Organic Compounds and Countermeasures for Healthy Housing, Tokyo, Japan, January 12-13, 2001.

[18] Edwards, B.: A short history of sustainable development. article, RIBA Publishing published in association with Earthscan. Copyright February 2010

https://www.thenbs.com/knowledge/a-short-history-of-sustainable-development

[19]http://www.pittsburghpa.gov/green/about.htm

[20] Benzu, J.: Importance of Sustainable Architecture in 21st Century. 2010

http://www.architecture-student.com/sustainable-design/importance-of-sustainable-

architecture-in-21st-century/

[21] Laurie, P.: How Building Green Got Its Start. 2011

http://www.brighthub.com/environment/green-living/articles/51601.aspx

[22] Saint-Gobain.: The difference between green, sustainable and healthy buildings. 2016 https://www.multicomfort.co.uk/the-difference-between-green-sustainable-and-healthybuildings/

[23] Fischer, D.: Do green building standards minimize human health concerns?. 2010 https://www.scientificamerican.com/article/do-green-building-standards-minimize-healthcooncerns/

[24] Building Design and Construction.:White Paper on Sustainability. page 4, November 2006 